\title{
The morphology of emphysema, chronic bronchitis, and bronchiectasis: Definition, nomenclature, and classification
}

\author{
B. E. HEARD, V. KHATChatourov, H. OTTO, N. V. PUTOV, AND L. SOBIN
}

From the Brompton Hospital, London, the World Health Organization, Geneva, the Institute of Pathology, Dortmund, West Germany, and the Institute of Pulmonology, Leningrad, USSR

The purpose of this document is to propose definitions and a morphological classification of emphysema, chronic bronchitis, and bronchiectasis. It is aimed at providing uniform, internationally acceptable standards to facilitate the comparability of data in the field of chronic non-specific respiratory diseases.

Received for publication 20 March 1979
The definitions and descriptions are intentionally brief and are designed to assist in the clear delineation of particular types of lesions. They are not intended to be full accounts of the diseases.

The definitions are based primarily on morphological characteristics. Pathogenetic and aetiological aspects are taken into consideration where necessary but are not sufficiently established to serve as the basis of a standardised classification at the present time.

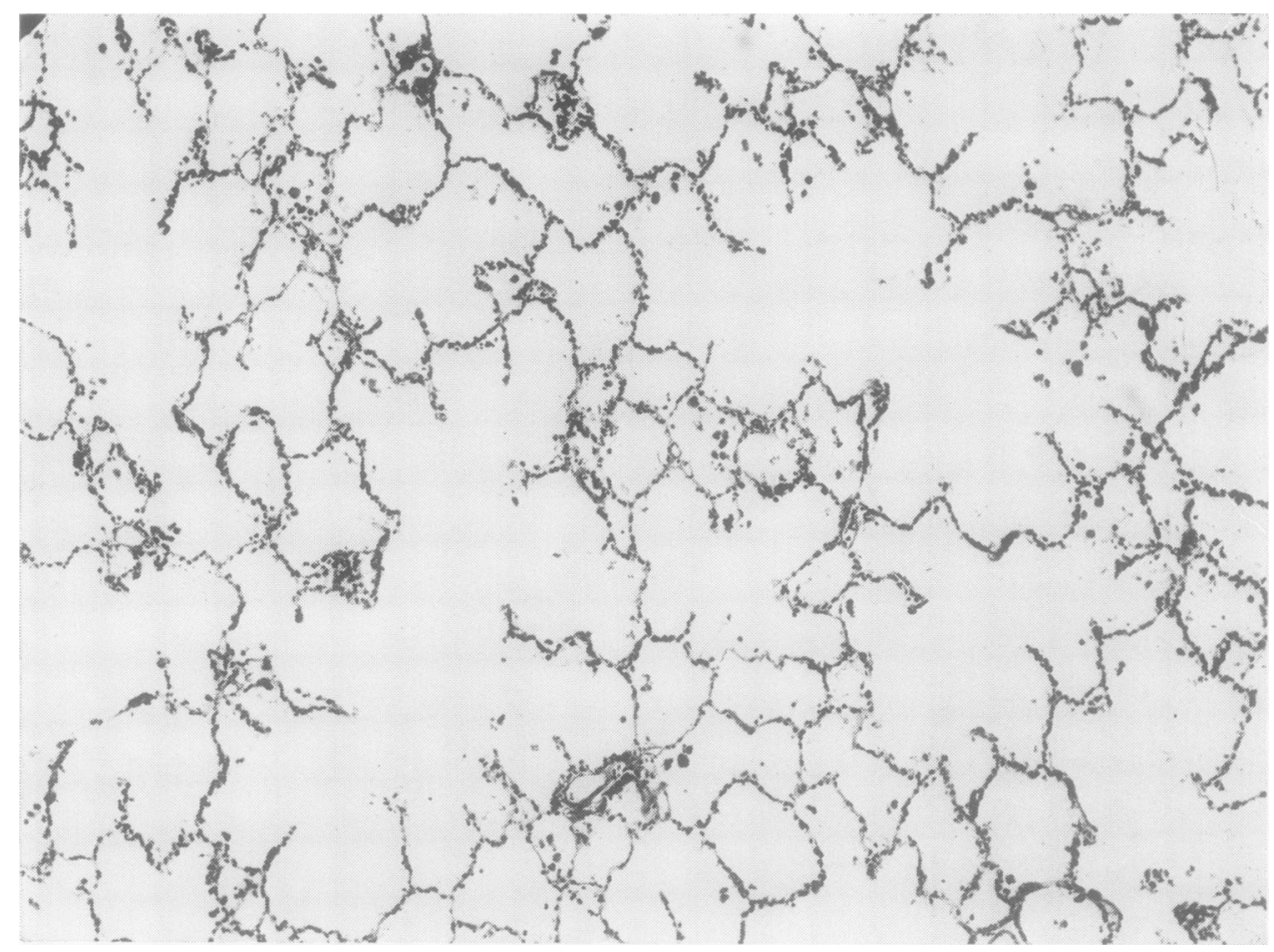

Fig. 1 Normal adult lung. Histological appearance after pressure-fixation with formol saline. The larger air-spaces are alveolar ducts with intact alveoli opening into them. Compare with Fig. 2 (Haematoxylin and eosin $\times 75$ ). 
Morphological classification of pulmonary emphysema

1 Vesicular emphysema
(a) Panlobular
(b) Centrilobular
(c) Paraseptal
(d) Irregular
(e) Unclassified

2 Interstitial emphysema

\section{Definitions and explanatory notes}

Pulmonary emphysema will be considered in the present account under the headings vesicular and interstitial emphysema.

1 VESICULAR EMPHYSEMA: an abnormal increase in the size of air spaces beyond the terminal bronchioles with destruction of air space walls.

Some definitions include in the term emphysema cases with irreversible dilatation of air spaces, referring to it as distensive emphysema (Heard, 1958; CIBA Guest Symposium, 1959); others consider it separate from emphysema and describe it as overinflation (American Thoracic Society, 1962).
For practical purposes histologically, emphysema is more easily defined as destruction of air space walls, since the degree of dilatation of air spaces can vary very much according to the method of fixation (Figs 1 and 2).

For carrying out subtyping and grading of emphysema, the macroscopic examination of large slices of lung is recommended rather than histological examination. Because of this macroscopic approach the lobule rather than the acinus has been chosen as the basis of the following definitions and hence the first-choice terms (Fig. 3).

Emphysema can be graded as mild, moderate, and severe.

(a) Panlobular emphysema ${ }^{1}$ (panacinar emphysema ${ }^{2}$ ): a form of emphysema that involves all air spaces beyond the terminal bronchioles in a relatively uniform manner throughout affected lobules (Figs 2 and 5).

(b) Centrilobular emphysema ${ }^{3}$ (centriacinar emphy-

${ }^{1}$ Term proposed by Wyatt (1959).

2Term proposed by CIBA Guest Symposium (1959).

${ }^{3}$ Term proposed by Leopold and Gough (1957).

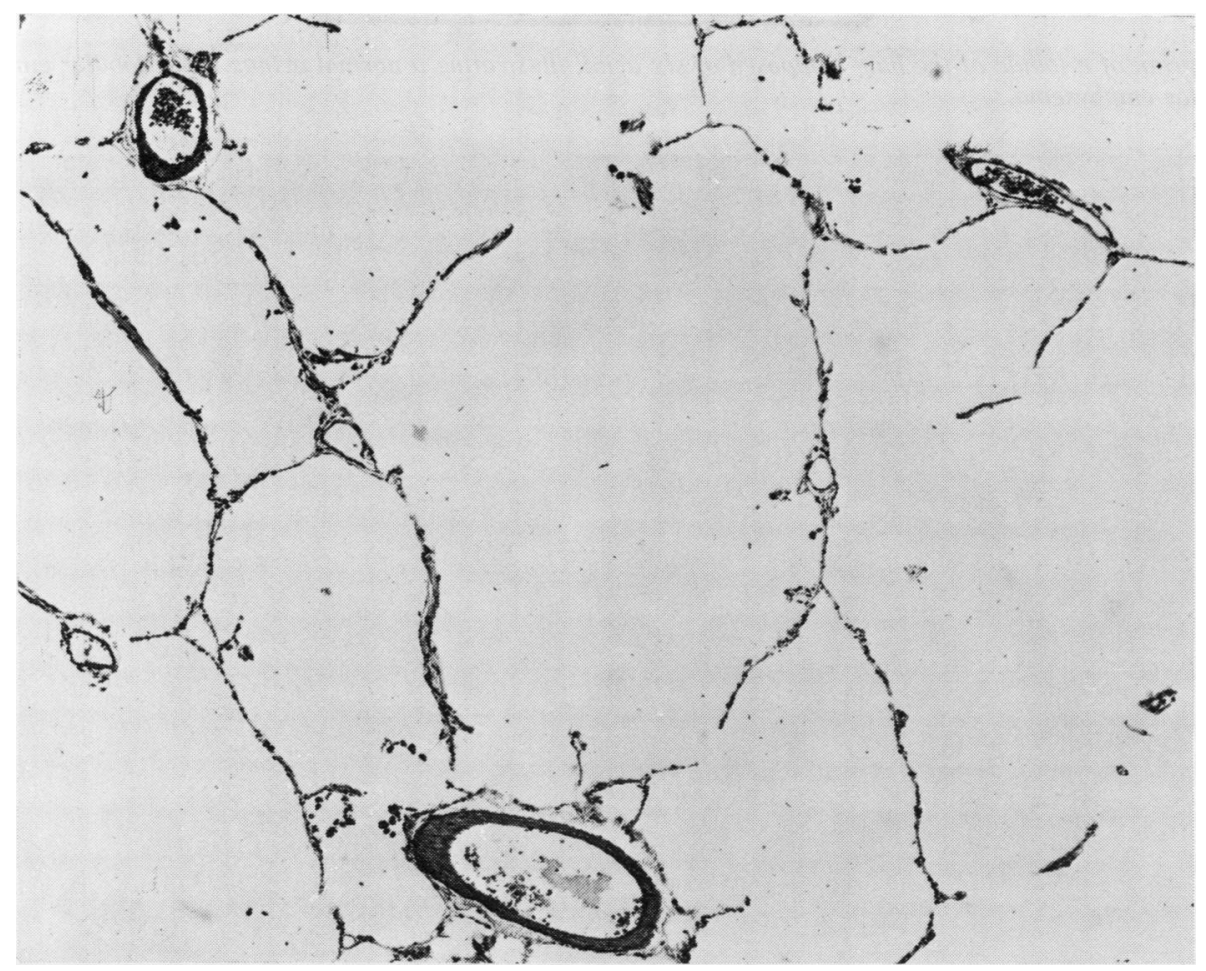

Fig. 2 Panlobular emphysema. Histological appearance of adult lung showing loss of many alveolar walls. Compare with Fig. 1 ( $H$ and $E \times 75)$. 


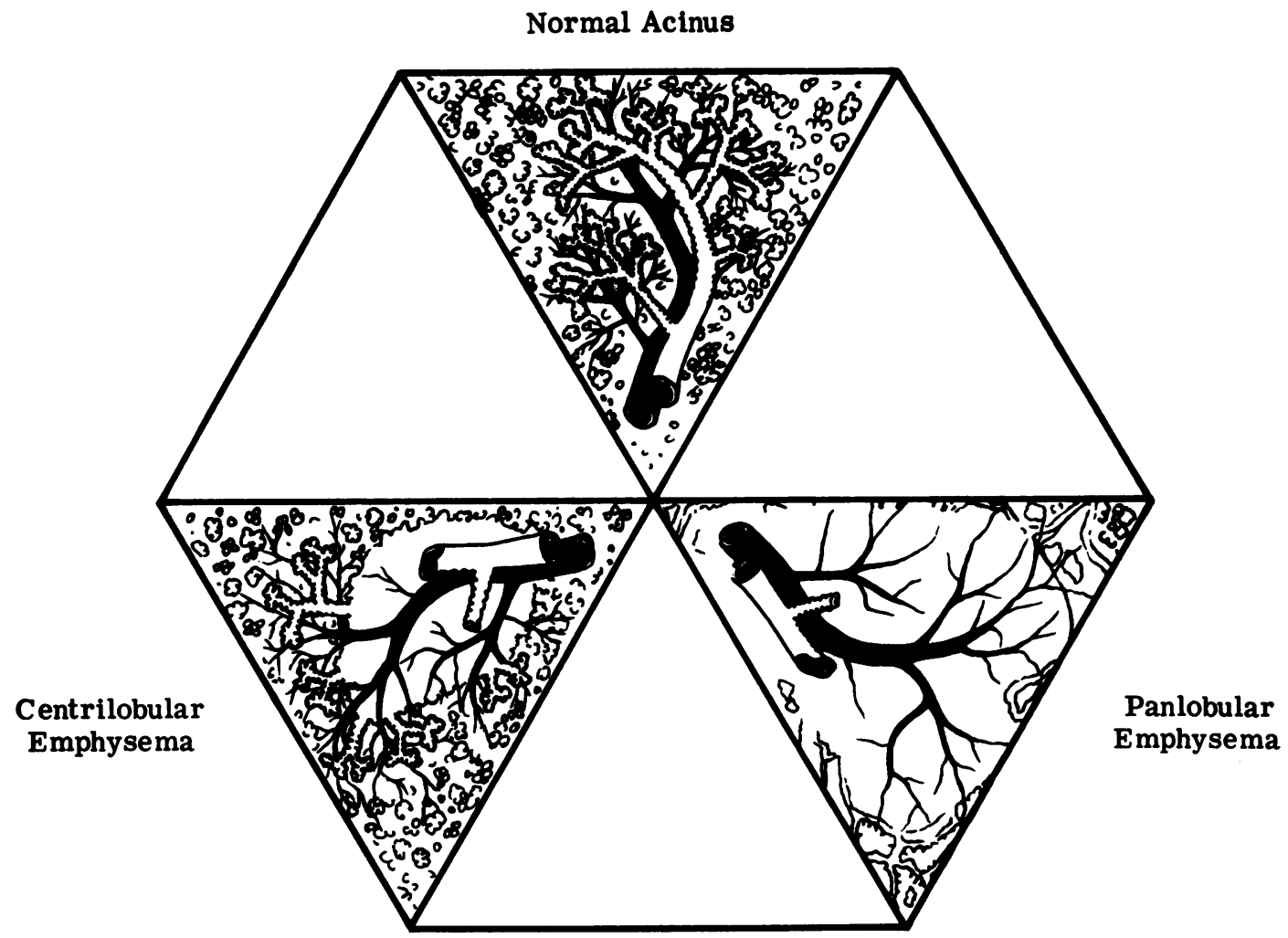

Fig. 3 Diagram of a lobule of the lung composed of six acini, illustrating a normal acinus, centrilobular emphysema, and panlobular emphysema.

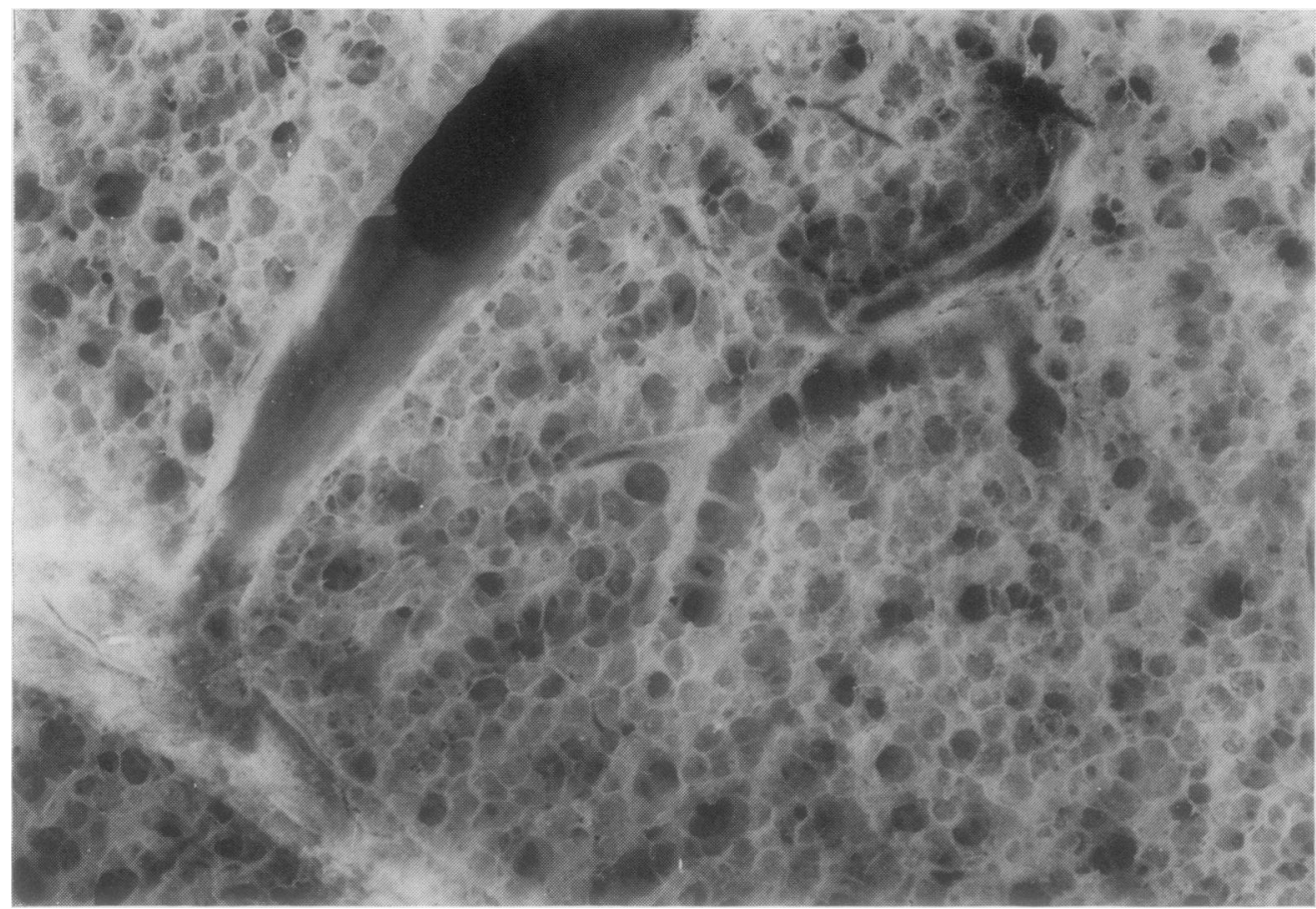

Fig. 4 Normal adult lung. Appearance of the cut surface for comparison with Figs 5 and 6 (Pressure-fixation, barium sulphate impregnations $\times 13 \cdot 7$ ). 


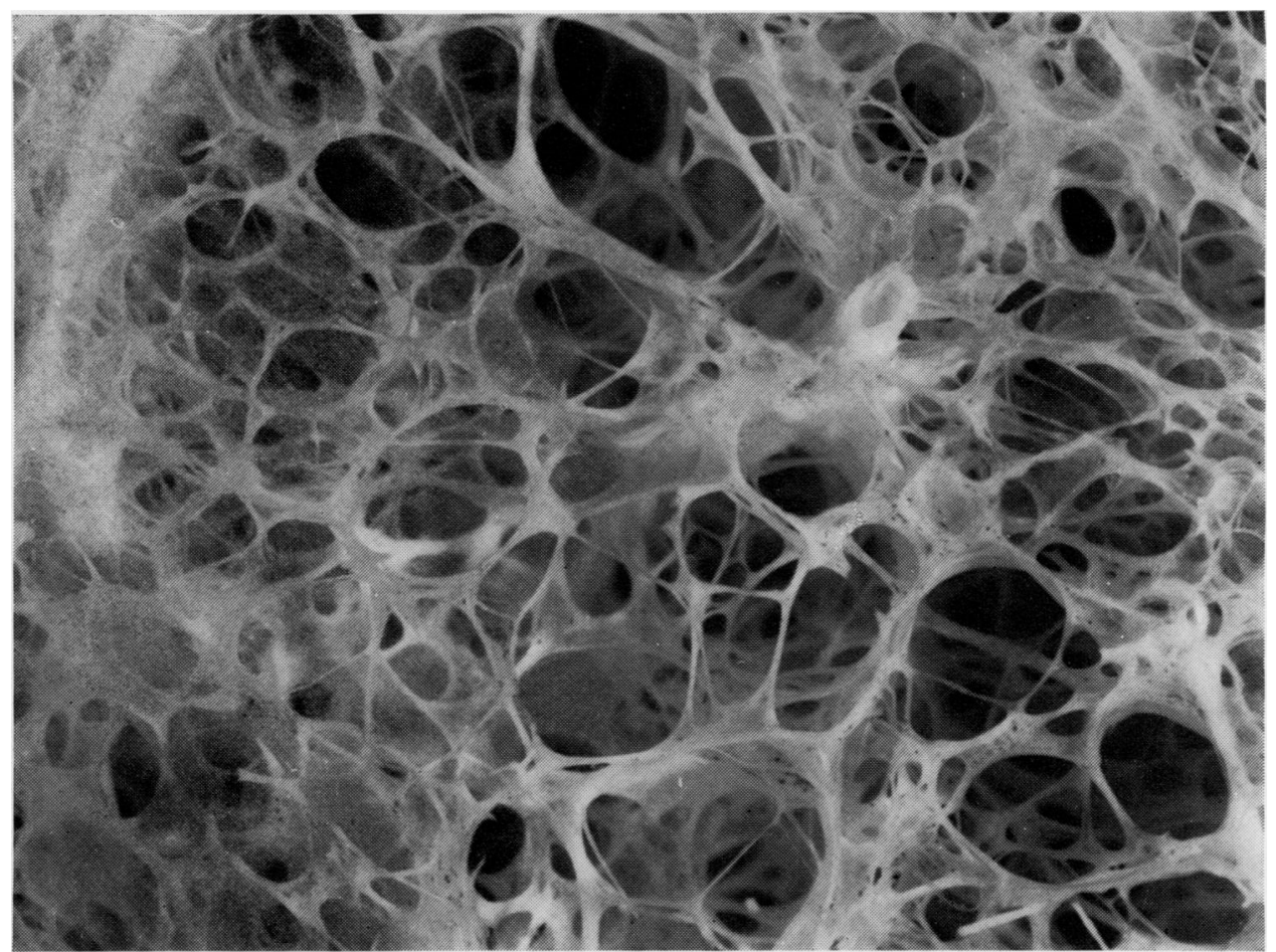

Fig. 5 Panlobular emphysema showing destruction of most of the alveolar walls. Compare with Fig. 4 (Pressure-fixation, barium sulphate impregnation $\times 15$ ).

sema $^{1}$ ): a form of emphysema that involves air spaces in the centre of lobules (Fig. 6).

The term centrilobular emphysema should be used whether or not there are deposists of dust within the lesion.

(c) Paraseptal emphysema $a^{2}$ a form that involves air spaces at the periphery of lobules (Fig. 7).

(d) Irregular emphysema ${ }^{3}$ : a form of emphysema that affects different parts of different lobules.

(e) Unclassified emphysema: a form of emphysema that does not fit any of the above categories. For example, cases in which there is difficulty in deciding between severe centrilobular and panlobular emphysema with empty lobules, or between centrilobular and irregular emphysema, shouid be categorised under $(e)$. NB This category should not be used, if possible, for mixtures of types $(a)-(d)$. In such cases with mixed morphology, the specific types should be

${ }^{1}$ Term proposed by Reid (1967).

${ }^{2}$ Term proposed by Heard $(1958 ; 1959 ; 1960 ; 1969)$.

${ }^{3}$ Term proposed by CIBA Guest Symposium (1959). recorded separately and categorised collectively according to the predominant type. A bulla is a focus of severe vesicular emphysema with a balloon-like appearance which has been defined as being more than $1 \mathrm{~cm}$ in the distended state (CIBA Guest Symposium, 1959). Cases of emphysema with bullae should be classified under types $(a)-(e)$ and not termed 'bullous emphysema'. A form of very localised emphysema with bullae is recognised; rupture and spontaneous pneumothorax occur. This form can be categorised under $(d)$, irregular emphysema.

Pulmonary fibrosis may be associated with dilatation of air spaces beyond the terminal bronchioles, producing a resemblance to a honeycomb. Such cases are classified as forms of pulmonary fibrosis rather than emphysema and have been described as emphysematous lung sclerosis or honeycomb lung (Otto, $1970 ; 1971)$.

The term senile emphysema (senile lung) is not in the above classification as it is not a morphological term; it is used by some authors to describe the condition of enlarged air spaces in elderly people, especially in the upper parts of the lungs. This change is common and can be regarded conveniently as within the normal range of air space size rather than 


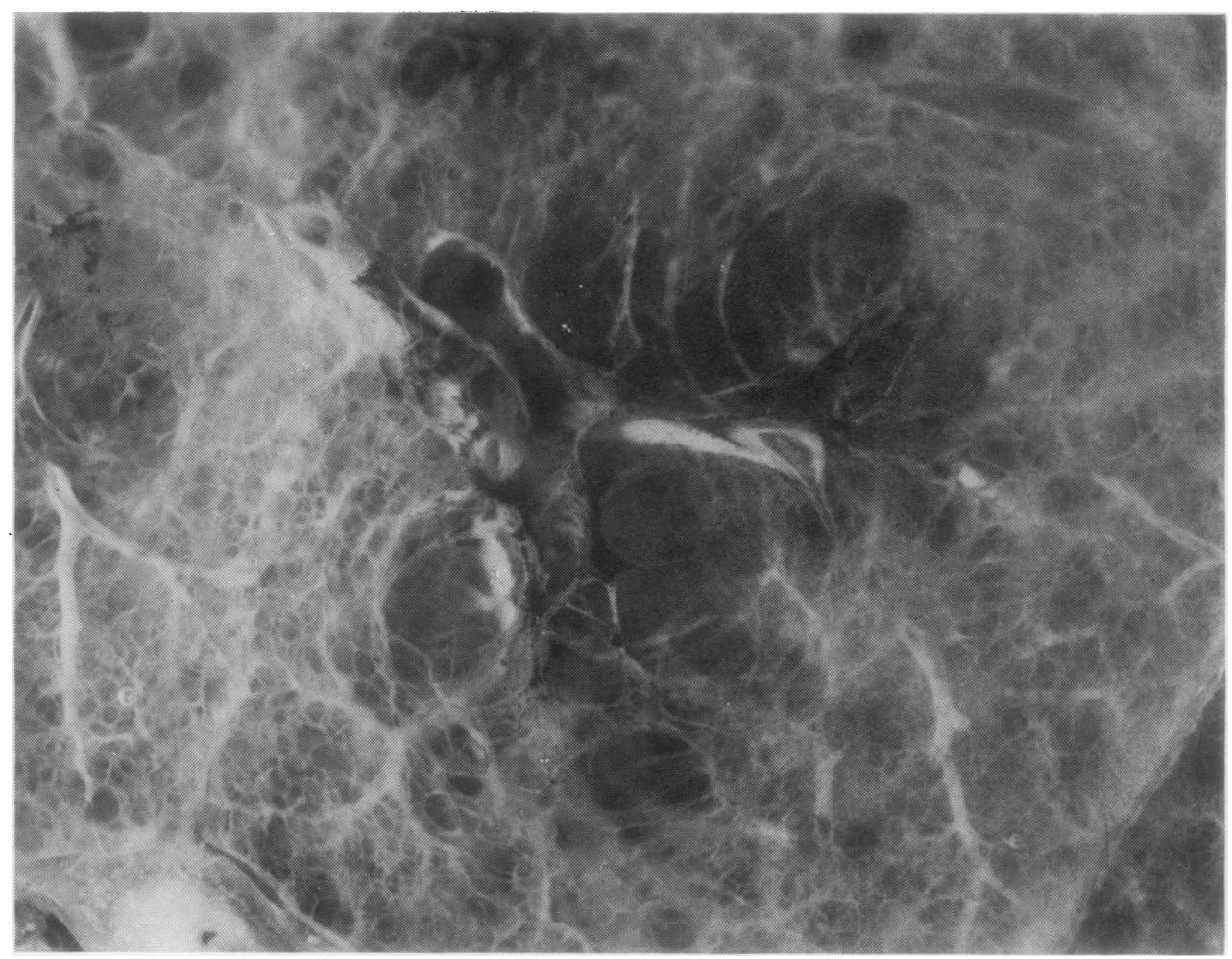

Fig. 6 Centrilobular emphysema showing bronchioles leading into the emphysematous lesions and normal alveoli surviving at the periphery of the lobule. (Pressure-fixation, barium sulphate impregnation $\times 11$ ).

a form of emphysema. Emphysema in elderly people should be categorised according to types $(a)-(e)$ above.

2 INTERSTITIAL EMPHYSEMA: a form of emphysema with inflation of the interstitial tissue of the lung by air or gas. Interstitial emphysema may spread to the mediastinum and subcutaneous tissue. A bleb is a marked balloon-like local collection of air in the interstitial tissues.

The term interstitial emphysema is preferred to interlobular emphysema because the latter fails to include emphysema of the interstitial tissue of the alveolar walls.

\section{Methods}

The best way to investigate a lung for emphysema is to infuse or inflate it with fixative. Subsequently the lung is immersed in fixative for a few days before being cut. For quantitative studies, pressure-fixation is necessary to ensure adequate inflation of all areas in a uniform manner (see Appendix).
If the findings are required quickly, one lung may be sliced an hour after infusion, although longer fixation gives better results.

After fixation the lung can be examined as wet whole-lung slices in water in a tray (facilitated by impregnation with barium sulphate) and/or after the preparation of paper-mounted whole-lung sections. Both methods are easy to carry out and not very time-consuming (see Appendix).

Several methods are available for measuring the amount of emphysema in lung slices, and all produce reliable results. They include a quick six-zone method, point-counting, comparison with photographs of standards, and a grid of 10 radiating segments (see Appendix).

CHRONIC BRONCHITIS: usually defined in clinical terms as a chronic inflammatory condition of the bronchi producing an increase in mucus secretion by the glands of the tracheobronchial tree resulting in the expectoration of mucus at some time of the day for at least three months of two consecutive years. 


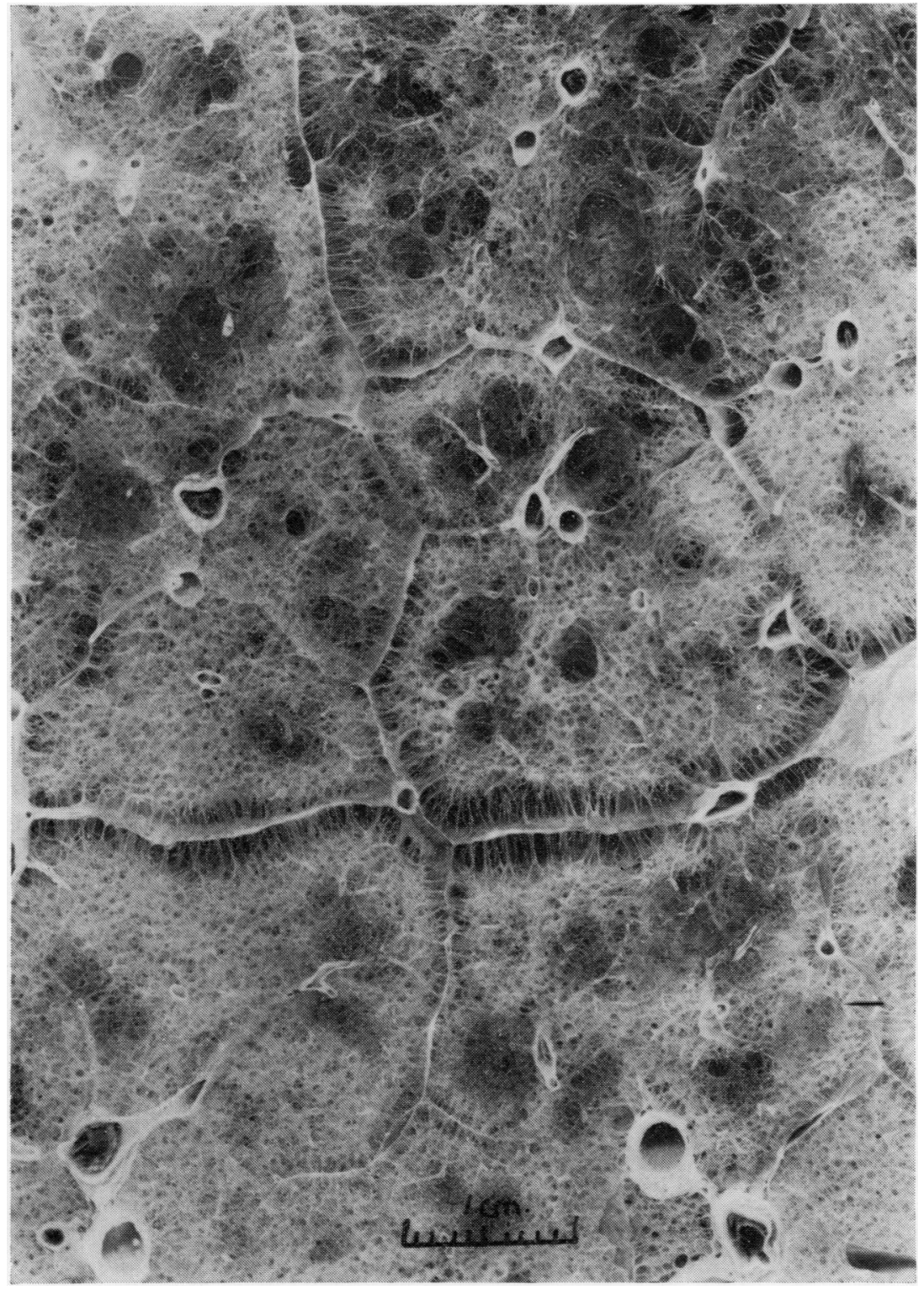

Fig. 7 Paraseptal emphysema showing destruction of air-spaces at the periphery of lobules. Centrilobular emphysema is present also. (Pressurefixation, barium sulphate impregnation).

Pathologically the bronchial wall may be thickened, and the following features may be observed histologically: enlargement of the mucous glands, dilatation of mucous gland ducts, an increase in the number of mucous cells in the acini of mucous glands, goblet cell hyperplasia and squamous metaplasia of the surface epithelium, a variable degree of chronic inflammatory cell infiltration. Chronic bronchiolitis is often associated with it, and there may be narrowing or obliteration of the lumen (Reid, 1967; Heard, 1969).
Bronchoscopic studies suggest that there may be several kinds of chronic bronchitis, but subdivision of these requires further pathological research.

\section{BRONCHIECTASIS}

Bronchiectasis: irreversible dilatation of bronchi, usually associated with inflammation.

The dilatation of a bronchus can be appreciated by comparing its diameter with that of the accompanying pulmonary artery, which is normally similar 


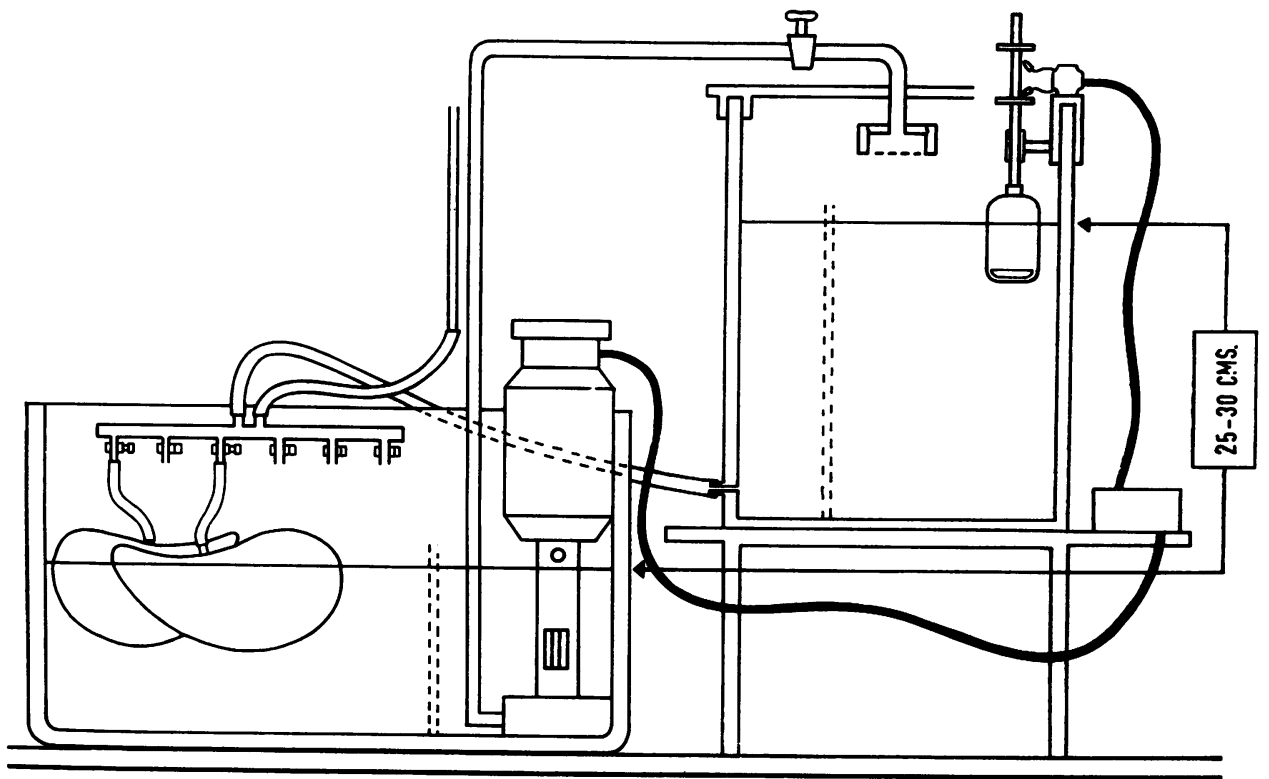

Fig. 8 Diagram of apparatus used for pressure-fixation of the lung. The centrifugal pump raises formalin to the upper container and is controlled by a float and switches (see Appendix).

(Otto and Rein, 1971).

Two basic patterns of bronchial dilatation are encountered macroscopically and are named, according to their shape, cylindrical and saccular.

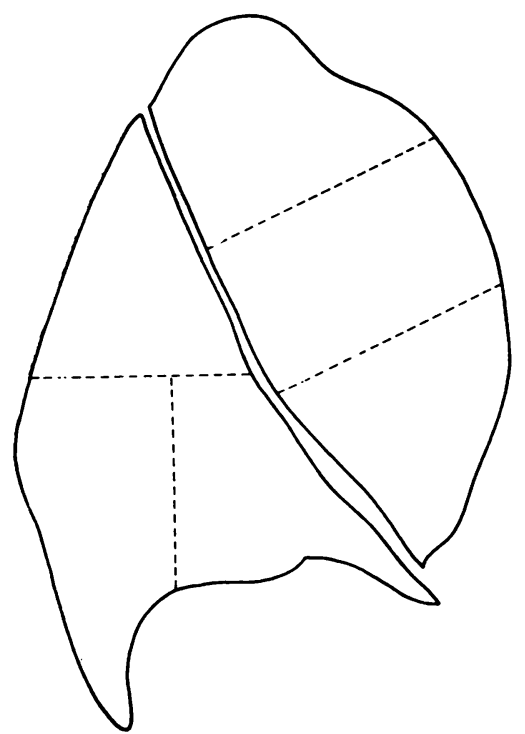

Fig. 9 Diagram showing six-zone method for measuring emphysema (see Appendix).
Cylindrical bronchiectasis: usually involves basal segments (Fig. 10), and the lumen often contains purulent mucus (Spencer, 1977). Fusiform bronchiectasis is included in this category. Microscopically the bronchial mucosa may be heavily infiltrated by lymphocytes and plasma cells, and lymphoid follicles may be present, especially in children. Bronchial glands and cartilage may be damaged or destroyed.

Saccular bronchiectasis (Spencer, 1977): intermediate bronchi are dilated to form rounded blind sacs (that usually do not communicate with the parenchyma) and may contain purulent mucus (Fig. 11). Histologically, there is chronic inflammation and fibrosis, and bronchial glands and cartilage may be destroyed.

Other terms, such as congenital and atelectatic bronchiectasis, refer to mechanisms rather than morphology. It is worth noting that bronchiectasis may be idiopathic or associated with chronic parenchymal inflammation, bronchial obstruction by foreign bodies or tumours or post-tuberculous scarring, chronic collapse of the lung, congenital anomalies, and cystic fibrosis (mucoviscidosis). There is a special form of cylindrical bronchiectasis which affects proximal bronchi as a consequence of the bronchial involvement in allergic bronchopulmonary aspergillosis. 


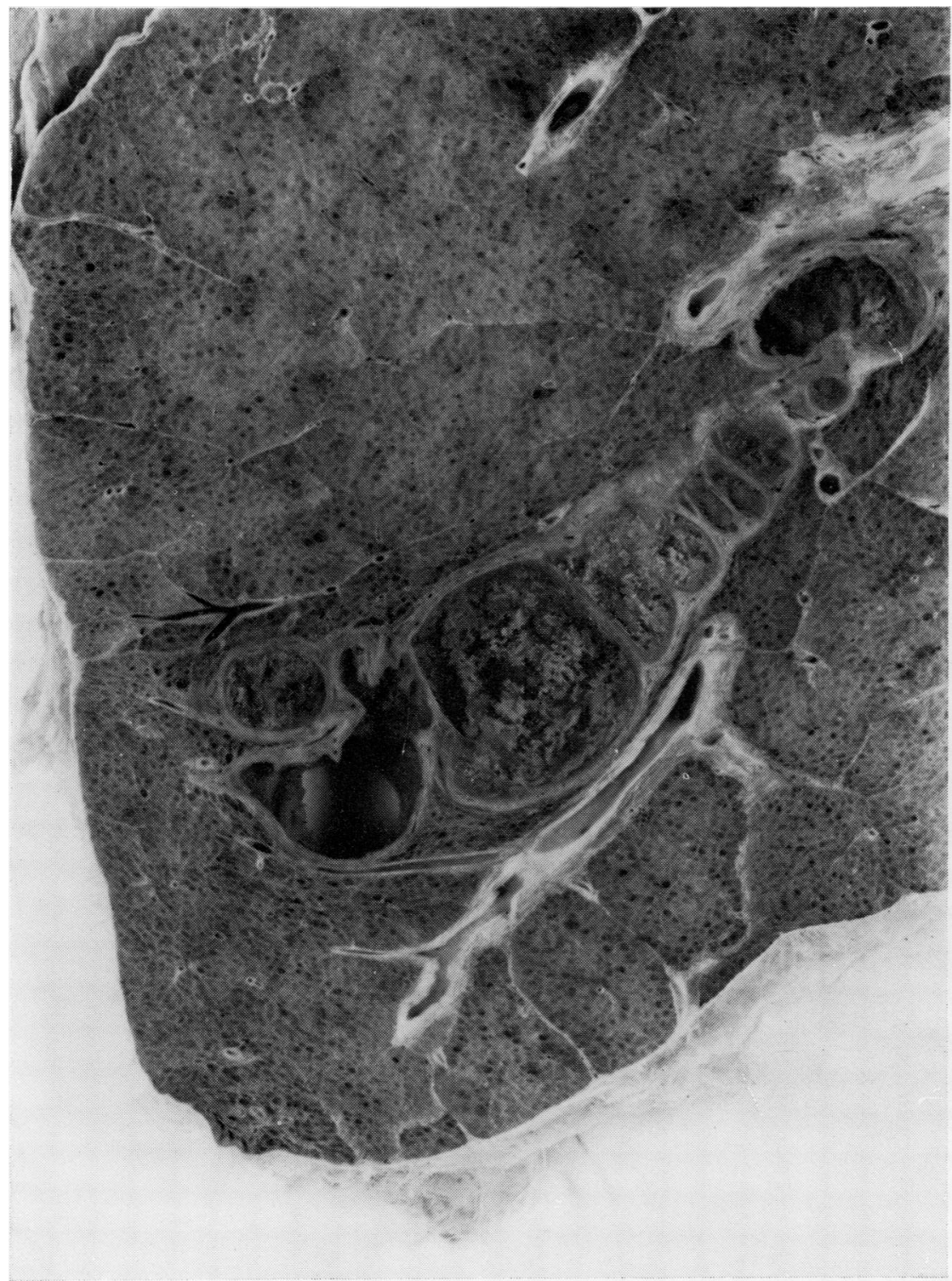

Fig. 10 Cylindrical bronchiectasis (Pressure-fixation, barium sulphate impregnation $\times 2 \cdot 3$ ).

\section{Appendix}

METHODS FOR PREPARING WET LUNG SLICES FOR EMPHYSEMA (Heard, 1958; 1959; $1960 ; 1969)$

(a) Method for fixing lungs under a standard pressure Mucus is sucked from the bronchi and a cannula is tied tightly into the main bronchus and attached to the tube from the upper container of $10 \%$ formol saline, as seen in Figure 8. The lung is placed in the lower container and allowed to distend slowly under a pressure of $25-30 \mathrm{~cm}$ of aqueous formalin which is then maintained for at least 24 hours but preferably 72 hours. When the level in the upper container falls below a certain mark, a float switch causes the pump to raise the level again. The lung is covered with a thin layer of muslin to keep it moist. This method distends air spaces to a degree comparable to full inspiration in life and prevents uneven distension, which is inevitable with specimens merely filled with formalin once and immersed in formalin. 


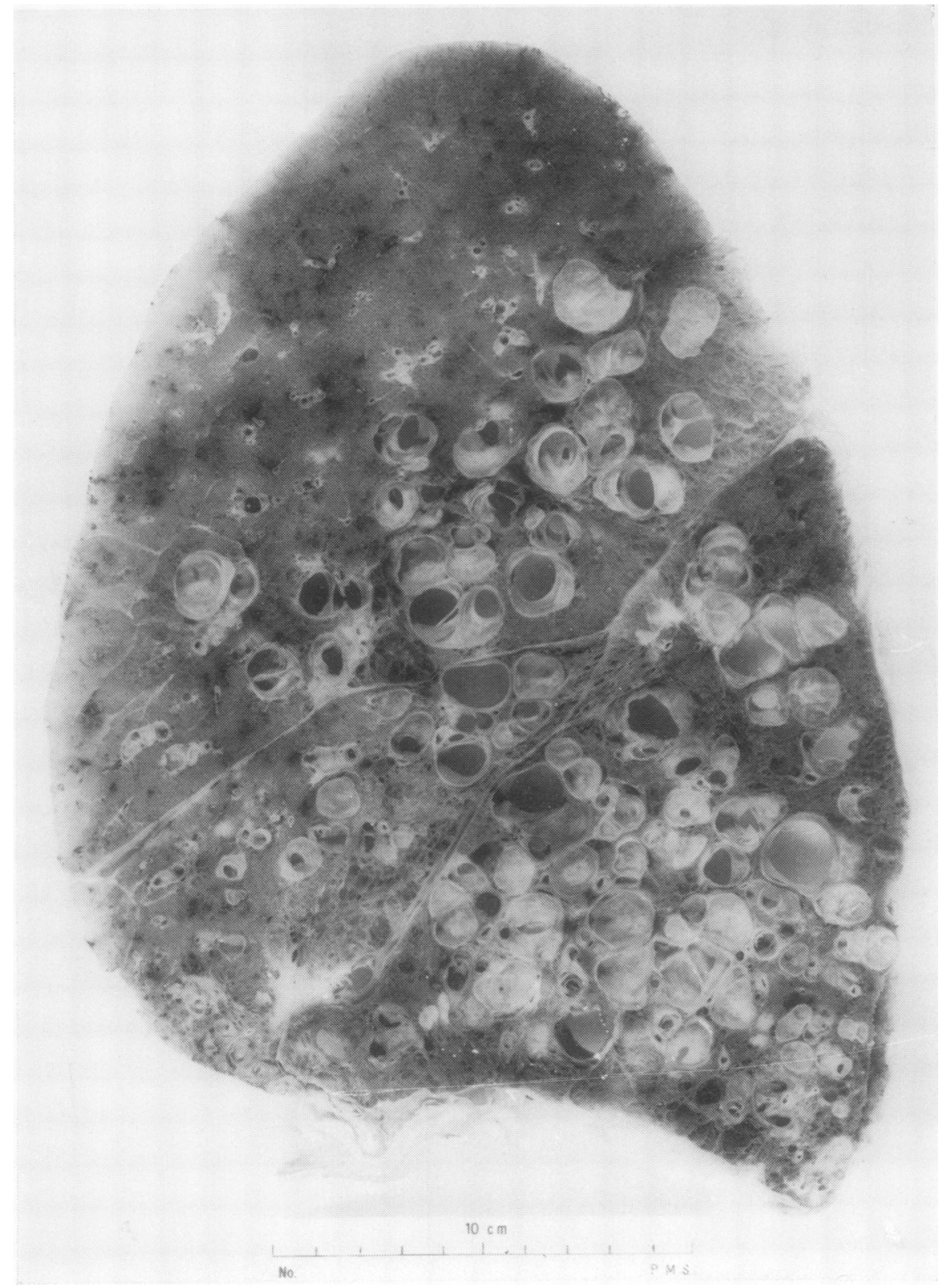

Fig. 11 Saccular bronchiectasis. (Pressure-fixation, barium sulphate impregnation).

(b) Method for cutting wet lung slices

The fixed lung may be placed, lateral surface downwards, on a board $25 \times 30 \mathrm{~cm}$ fitted down the two long sides with knife-supports raised $8 \mathrm{~mm}$ above the board. A long, very sharp knife is rested on the raised edges, and several anteroposterior slices are cut from the lung for examination.

(c) Method for barium sulphate impregnation of wet lung slices for emphysema

A selected slice of lung is lightly squeezed free of excess water and placed flat in a tray $25 \times 30 \mathrm{~cm}$ containing 1 litre of saturated aqueous barium nitrate at room temperature for 1 minute. It is pressed intermittently with the finger tips (protective gloves should be worn) to encourage the solution to enter the depths of the slice, then gently squeezed to return most of the solution to the tray, and transferred to a similar tray of 1 litre saturated sodium sulphate, also at room temperature. A white cloud of precipitated barium sulphate appears, and after 1 minute the slice is washed in water and examined in a 
tray of clean water by naked eye and hand-lens or dissecting microscope. The method renders the normally translucent alveolar walls opaque and more easily visible in water, and emphysematous changes thus become more easily seen. Subsequent histology is not impaired.

Photography of emphysema is improved, and the whitening is permanent and suitable for museum preparations.

METHOD FOR PREPARING WHOLE LUNG SECTIONS (Gough and Wentworth, 1949, 1960) Thick slices of a lung fixed in formalin in the distended state are embedded in gelatin, and sections cut $400 \mu$ thick on a large microtome are mounted on paper. The sections are suitable for filing with other papers and for sending through the mail. Care must be taken during processing to prevent digestion of the gelatin by enzymes from the tissues of the lung or from contaminating organisms (Medical Research Council Committee, 1975).

\section{METHODS FOR MEASURING EMPHYSEMA}

(a) A rapid six-zone method for measuring emphysema (Heard and Izukawa, 1964)

The six zones are illustrated in Figure 9. A prepared wet slice, impregnated with barium sulphate, is examined with a hand lens or dissecting microscope to assess the change in detail, and then by the naked eye the area is divided visually into six zones of equal area (using metal probes). Each zone is awarded up to 3 units according to the proportion of the area emphysematous. Half units are also counted. The result is stated as a number of units out of 18 total units. The percentage of the slice that is emphysematous is obtained by multiplying by $5 \cdot 5$.

\section{(b) A point-counting method for measuring emphysema} (Dunnill, 1962)

Wet lung slices or paper-mounted whole-lung sections may be examined under a transparent plastic grid carrying an array of points (or small holes) arranged in a hexagonal pattern (eg, $4 \mathrm{~mm}$ apart). At each point a record is counted of normal lung, emphysematous lung, or non-alveolated tissue such as blood vessel or bronchus. Emphysema may be expressed as a percentage of the area of a slice, or several slices, or of the volume of a lung.

(c) A method for measuring emphysema using comparison with photographs of standards (Thurlbeck et al., 1970)

Paper-mounted whole-lung sections are prepared and compared with a standard set of photographs of selected whole-lung sections. The method is quick, and the results are similar from different observers. The scores represent arbitrarily derived grades of severity.

(d) A method for measuring emphysema using a grid of 10 radial segments (Ryder et al., 1969; Gough et al., 1967)

A plastic grid marked by a circle divided by five straight lines into 10 equal segments is placed over a wet slice or paper-mounted whole-lung section with the centre point over the mid-point of the interlobar fissure and with any one of its lines lying along the fissure. Emphysema in each segment is assessed as 0 absent, 1 mild, 2 moderate, 3 severe, giving a maximum total of 30 points.

METHODS FOR QUANTITATING HISTOLOGICAL CHANGES OF CHRONIC BRONCHITIS

The main pathological evidence for the mucous hypersecretion observed clinically in chronic bronchitis is enlargement of the bronchial mucous glands. There are three methods for measuring this.

(a) Gland/wall thickness ratio method (Reid, 1960; 1967)

Transverse sections of main or lobar bronchi are examined by means of a graticule set in the eyepiece of a microscope. At a site where cartilage is roughly parallel to the surface epithelium, the distance from the epithelium to the cartilage $(\mathrm{W})$ is measured and, at the same point, the depth of the mucous gland layer $(G)$. The mean of several measurements is compared with a normal range $0 \cdot 14-0 \cdot 26$ for $\frac{G}{W}$.

(b) Cut-out and weigh method (Restrepo and Heard, 1963a and b)

Transverse sections of selected bronchi are projected at a magnification of $\times 10$ on plain white card, a measured area of which is first weighed. The outlines of the bronchial glands are then drawn on the card and cut out and weighed. The actual areas of the glands in sections can be obtained in this way and evaluated by comparison with controls. This method can also be used to measure cartilage and whole walls (Restrepo and Heard, 1964).

\section{(c) Point-counting method}

Sections of bronchi are projected on a screen marked with a grid of points. The number of points corresponding to bronchial glands (or muscle, etc) is counted and is expressed as the areas of glands (or muscle, etc) in absolute numbers in selected bronchi (Macleod and Heard, 1969; Hossain and Heard, 1970) or as a ratio to points corresponding to cartilage, expressed as a percentage (Dunnill et al., 1969). 
This work was initiated and supported by the World Health Organization. We are grateful to those pathologists who provided helpful criticisms and suggestions. Figures 1, 2, 5, 8, and 9 are from Pathology of Chronic Bronchitis and Emphysema by Heard (1969) and reproduced by permission of Churchill Livingstone, Edinburgh. Figures 4, 5, 6, 7, 10, and 11 were photographed for Dr B. Heard by Mr W. Brackenbury at the Postgraduate Medical School, London, and Figs 1 and 2 by the Medical Illustration Service of the University of Edinburgh. The diagram in Fig. 3 was prepared by the Department of Medical Illustration, Royal Marsden Hospital, London. Figure 8 is reproduced by permission of the Editor of the American Review of Respiratory Disease. Figures 10 and 11 are reproduced by permission of the Editor of the British Medical Journal, (Fig. 10-2, 1468-1476, 1959; Fig. 11-2, 352-355, 1965).

\section{References}

American Thoracic Society (1962). Chronic bronchitis, asthma and pulmonary emphysema. A statement by the Committee on Diagnostic Standards for Nontuberculous Respiratory Diseases. American Review of Respiratory Diseases, 85, 762-768.

CIBA Guest Symposium (1959). Terminology, definitions, and classification of chronic pulmonary emphysema and related conditions. Thorax, 14, 286-299.

Dunnill, M. S. (1962). Quantitative methods in the study of pulmonary pathology. Thorax, 17, 320-328.

Dunnill, M. S., Massarella, G. R., and Anderson, J. A. (1969). A comparison of the quantitative anatomy of the bronchi in normal subjects, in status asthmaticus, in chronic bronchitis, and in emphysema. Thorax, 24, 176179.

Gough, J., Ryder, R. C., Otto, H., and Heller, G. (1967). Vergleichende morphologische Untersuchungen zur Häufigkeit des Lungenemphysems. Frankfurter Zeitschrift für Pathologie, 77, 317-327.

Gough, J., and Wentworth, J. E. (1949). The use of thin sections of entire organs in morbid anatomical studies. Journal of the Royal Microscopical Society, 69, 231-235. Gough, J., and Wentworth, J. E. (1960). Thin sections of entire organs mounted on paper. In Recent Advances in Pathology: 7th edition, edited by C. V. Harrison, pp. 80-86. Churchill, London.

Heard, B. E. (1958). A pathological study of emphysema of the lungs with chronic bronchitis. Thorax, 13, 136149.

Heard, B. E. (1959). Further observations on the pathology of pulmonary emphysema in chronic bronchitics. Thorax, 14, 58-70.

Heard, B. E. (1960). Pathology of pulmonary emphysema. Methods of study. American Review of Respiratory Diseases, 82, 792-799.
Heard, B. E. (1969). Pathology of Chronic Bronchitis and Emphysema, pp. 65-66. Churchill, London.

Heard, B. E., and Izukawa, T. (1964). Pulmonary emphysema in fifty consecutive male necropsies in London. Journal of Pathology and Bacteriology, 88, 423-431.

Hossain, S., and Heard, B. E. (1970). Hyperplasia of bronchial muscle in chronic bronchitis. Journal of Pathology, 101, 171-184.

Leopold, J. G., and Gough, J. (1957). The centrilobular form of hypertrophic emphysema and its relation to chronic bronchitis. Thorax, 12, 219-235.

Macleod, L. J., and Heard, B. E. (1969). Area of muscle in tracheal sections in chronic bronchitis, measured by point-counting. Journal of Pathology, 97, 157-161.

Medical Research Council Committee (1975). Quantitative assessment of chronic non-specific lung disease at necropsy. Thorax, 30, 241-251.

Otto, H. (1970). Die Atmungsorgane. In Handbuch der allgemeinen Pathologie, Bd. 3, Teil 4, pp. 1-204. Springer, Berlin.

Otto, H. (1971). Definition und Morphologie des Emphysems. Beiträge zur Pathologie, 142, 221-228.

Otto, H., and Rein, J. G. (1971). Morphologische Definition und Diagnostik von Bronchiektasen. Beiträge zur Pathologie, 143, 70-83.

Reid, L. (1960). Measurement of the bronchial mucous gland layer: A diagnostic yardstick in chronic bronchitis. Thorax, 15, 132-141.

Reid, L. (1967). The Pathology of Emphysema. Lloyd-Luke, London.

Restrepo, G., and Heard, B. E. (1963a). The size of the bronchial glands in chronic bronchitis. Journal of Pathology and Bacteriology, 85, 305-310.

Restrepo, G. L., and Heard, B. E. (1963b). Mucous gland enlargement in chronic bronchitis: extent of enlargement in the tracheo-bronchial tree. Thorax, 18, 334-339.

Restrepo, G. L., and Heard, B. E. (1964). Air trapping in chronic bronchitis and emphysema. American Review of Respiratory Diseases, 90, 395-400.

Ryder, R. C., Thurlbeck, W. M., and Gough, J. (1969). A study of interobserver variation in the assessment of the amount of pulmonary emphysema in paper-mounted whole lung sections. American Review of Respiratory Disease, 99, 354-364.

Spencer, H. (1977). Pathology of the Lung, 3rd edition, Volume 1, pp. 130-149. Pergamon Press, Oxford.

Thurlbeck, W. M., Dunnill, M. S., Hartung, W., Heard, B. E., Heppleston, A. G., and Ryder, R. C. (1970). A comparison of three methods of measuring emphysema. Human Pathology, 1, 215-226.

Wyatt, J. P. (1959). Macrosection and injection studies of emphysema. American Review of Respiratory Diseases, $80(1)$, part 2, 94-103.

Requests for reprints to: Professor B. E. Heard, Cardiothoracic Institute, Brompton Hospital, Fulham Road, London SW3, UK. 